\title{
Memorias de la secularización: el registro de las transformaciones en el escenario religioso brasilero a través de las estadísticas de individuos identificados como sin religión
}

\author{
Memories of secularization:recording the transformations in the Brazilian \\ religious space through statistics about people identified as without religion
}

Denise dos Santos Rodrigues Doctora en Ciencias Sociales y en Filosofía por la Universidade do Estado do Rio de Janeiro, UERJ, y maestra en Ciencia Política por el Instituto Universitario de Pesquisa do Rio de Janeiro, IUPERJ Municipalidad de la ciudad de Rio de Janeiro, Brasil denise_rois@yahoo.com.br

Artículo de investigación

Fecha de recepción: 14 de marzo de 2013• Fecha de aprobación: 5 de julio de 2013

\section{RESUMEN}

A propósito del incremento de islámicos en Europa y de la población sin religión, en países como Estados Unidos y Brasil -según se verifica en los sucesivos censos al respecto-, el artículo expone algunas de las más relevantes teorías sobre la secularización, pertinentes para la comprensión de las nuevas manifestaciones de la espiritualidad en el mundo comtemporáneo, donde la religión parece replegarse cada vez más en la esfera privada.

Palabras clave: sin religión, secularización, desinstitucionalización, censos.

\section{Abstract}

Commenting on the increase of Islamic people in Europe and the people without religion in countries like the United States and Brazil -according to verified in subsequent censuses about it-, the article exposes some of the most important theories of secularization, relevant 
for understanding new manifestations of spirituality in the contemporary world where religion seems increasingly withdraw into the private sphere.

Keywords: Without religion, secularization, census.

\section{INTRODUCCIÓN}

Muchos teóricos proyectan para el futuro de la población mundial un escenario secular, que acompañaría los avances tecnológicos y científicos, separando al individuo de las antiguas mitologías. Mientras tanto, observamos en el siglo XXI la subsistencia y el reavivamiento de las manifestaciones de religiosidad, a veces más radicales, a veces más flexibles, más allá del surgimiento de identidades individuales.

El panorama religioso es dinámico y heterogéneo, marcado por flujos: en Europa crece el número de islámicos; en los países abajo de la línea ecuatorial, crece el de pentecostales, mientras que en Estados Unidos y Brasil, el número de personas sin religión, crece velozmente conquistando seguidores de los antiguos grupos tradicionales. Tenemos, entonces, transformaciones que evidencian el interrelacionamiento del campo religioso con la cultura moderna, reproduciendo tendencias de un nuevo estilo de vida. Surgen nuevas maneras de creer, en estrecha relación con una apropiación diferenciada del concepto de religión, que no está necesariamente sujeta a la existencia de una institución religiosa. Es en este sentido que proponemos aquí un rescate de diferentes teorías sobre los procesos de secularización y laicismo que, si no se confirmaran como el destino de la humanidad, constituirían procesos históricos que abrieran camino para que la esfera religiosa pudiese ser reconfigurada.

Cuando pensamos en la identificación de un individuo que se define y se clasifica en los censos brasileros como alguien sin religión, la tendencia es que, en un primer momento, lo analicemos a través del prisma de la secularización. Más adelante, cuando corroboramos las diferentes tipologías que existen en esta categoría censitaria, comprendemos su significado para la contemporaneidad. Cuando decidimos investigar la categoría censitaria de los sin religión en el caso brasilero, en donde el 
grupo viene creciendo a un ritmo acelerado en cada década, estábamos motivados principalmente por la escases de material sobre el tema, más allá de la oscuridad en la cual esta categoría parecía inmersa, lo que develamos en la conclusión de la investigación. Frente a la inexistencia de una institución de referencia para localizar el grupo, lo que facilita la investigación en el campo de la religión, construimos una red de individuos que se declaraban sin religión, a quienes entrevistamos. Nos concentramos en los habitantes de la Región Metropolitana del Estado de Rio de Janeiro, la de mayor representación del grupo desde el Censo 2000, donde descubrimos su composición heterogénea.

Encontramos mezclados, en la misma categoría censitaria, desde ateos y agnósticos, totalmente incrédulos o dudosos de la creencia de lo trascendente, a los que clasificamos como individuos sin religión "sin religiosidad", también individuos que mantenían su fe en Dios o en algún otro tipo de fuerza trascendente, que clasificamos como sin religión "con religiosidad". En el primer grupo reunimos aquellos que sin vínculos institucionales con religiones o con lo mágico; de modo general, ellos adoptan una postura absolutamente materialista para todas las cosas. En el segundo grupo, juntamos aquellos que no rechazaron lo trascendente, solo cambiaban su religiosidad para un ámbito muy privado, estableciendo una relación particular o aun íntima con sus representaciones. De hecho, es este segundo tipo que predomina en la categoría censitaria de los sin religión, lo que sugiere diferentes comprensiones del concepto de religión, que no siempre está subordinado al perteneciente institucional.

Conviene destacar que, hasta 1950, esta categoría era contabilizada junto con los individuos sin declaración de religión, o que no informaron nada al respecto de su condición de religiosidad, mezclando las dos situaciones. A partir de 1960 ese grupo fue redefinido, aislando solamente a aquellos que se declaraban como sin religión, que comenzaba a aumentar gradualmente, hasta pasar de $1.6 \%$ en 1980, a $4.8 \%$ en 1991 y $7.3 \%$ en el $2000^{1}$. Aunque todavía predominante en Brasil, entre 1980 y 1991, la religión católica tuvo una pérdida de $5.7 \%$ de fieles, en contraste con un aumento de $2.4 \%$ para los evangélicos y de un $3.1 \%$ para los sin religión. En el 2000, esta pérdida fue aumentando a $9.4 \%$, contra un aumento de $2.7 \%$ de los

1 Consulta de los Censos Demográficos de 1950 e incluso de los de 1960, 1970, 1980, 1991. 
sin religión y, aún más, de $6.6 \%$ de los evangélicos. Resultados del Censo de 2010 muestran que, a pesar de toda la revitalización proporcionada principalmente por la Renovación Católica Carismática, la pérdida de los católicos se acentuó a 64.63 \%.

Solamente en esta edición, la categoría de los sin religión fue aparentemente dividida en grupos de ateos, agnósticos y sin religión (categoría genérica). Pero aun así no traduce con exactitud su composición ni representación, pues esta distribución depende de las informaciones que el entrevistado añade espontáneamente, especificando, por ejemplo, si es sin religión, ateo, o si es evangélico de Asambleas de Dios, orientando hacia el grupo al que pertenece. Lo que sucede es que los censos brasileros siguen teniendo una única pregunta para catalogar a la variedad existente en el campo religioso: “¿cuál es su religión?”, lo que limita el campo, dificultando, entre otras, la identificación de múltiples prácticas o creencias. Si, en el caso de los sin religión el entrevistado no se clasifica simultáneamente como ateo o como agnóstico, es agregado a un grupo mayor, los de sin religión, para los que responden simplemente "sin religión". Así, en el censo del 2010 los "sin religión" -categoría genérica- representan el $7.65 \%$ del grupo, al lado de $0.32 \%$ de ateos y de $0.07 \%$ de agnósticos que se declararon como tal. Pero entendemos que en el grupo genérico sin religión pueden estar ocultas otras variedades.

A pesar de eso, la evolución de los sin religión no se refleja solamente en la identificación de un grupo que no se adhiere a las instituciones religiosas tradicionales, sino que también se evidencia en un cambio de comportamiento derivado de transformaciones en el escenario internacional, permitiendo que los individuos se apropiasen de sus libertades civiles, apropiándose de la libertad de pensamiento, culto y creencia, lo que permite el cambio de lugar de la religión: de lo público para lo privado. Tenemos, así, un proceso de destradicionalización, que puede ser más bien entendido cuando es abordado en el debate de las teorías de secularización.

\section{MeMORIAS SEleCtAS DE LOS PROCESOS DE SECULARIZACIÓN}

Todas las transformaciones derivadas del desarrollo de las ciudades, de la industrialización, del avance tecnológico, de los descubrimientos científicos y de la 
amplitud de los canales de información, parecían amenazar el pensamiento religioso. En ese panorama, el individuo emancipado de los mitos de origen, de los dogmas, de las autoridades eclesiásticas, se liberaría para buscar las respuestas a sus dudas fuera de los libros sagrados. Mientras tanto, a pesar de todos los pronósticos que anunciaban el fin de la religión, esta no desapareció en sus formas institucionales, pero se multiplicó en diversas formas de creer, adaptándose a las nuevas condiciones de un mundo movido por la reflexividad. Hubo una reorganización de lo religioso y también del entendimiento del sentido y apropiación de la religión. Frente al surgimiento de un nuevo estilo de vida, la autonomización de los individuos del dominio religioso institucional no implica necesariamente un rompimiento de su relación con lo trascendente, ni le impide tener experiencias de ofertas de bienes religiosos en un mercado plural. Estamos frente, por una parte, a un momento de declive de las religiones tradicionales y por otro, de la manifestación de nuevas formas de relacionarse con lo divino a partir del ejercicio de las libertades de creencia, culto y expresión del pensamiento, propiciadas por movimientos de laicización y procesos de secularización reivindicados en varios momentos de la historia mundial.

Mucho se ha discutido sobre la canalización del proceso de la secularización en todo su alcance, en diferentes corrientes de las ciencias humanas y sociales. En Sociología, por ejemplo, hay un extenso debate donde se destacan autores como David Martin, Steve Bruce, José Casanova y Karel Dobbelaere ${ }^{2}$, entre otros de los cuales no nos vamos a referir en este artículo. Elegimos una selección de autores clásicos y contemporáneos, inclusive aquellos que hicieron una revisión bibliográfica interesante, para trazar algunos de los aspectos más relevantes de la secularización que contribuyen a la reflexión sobre nuestro objeto de estudio, las personas sin religión, emblemático de la crisis de pertenencia institucional en la actualidad.

2 En el ámbito internacional, hay obras totalmente dedicadas al tema de la secularización como, por ejemplo: Bruce, Steve. God is Dead: secularization in the West. United Kingdom: Blackwell Publishing, 2007; Martin, David. On Secularization: towards a revised general theory. England: Ashgate, 2005 y Martin, David. A General Theory of Secularization. Oxford: Basil Blackwell, 1978; Casanova, José. Religiones públicas en el mundo moderno. Madrid: PPC, 2000; y también Dobbelaere, Karel. Secularization: a Multi-Dimentional Concept. London: Sage Publication, 1981. En el entorno nacional hay autores como, por ejemplo, Flávio Pierucci, el cual está incluido en nuestro estudio. 
En su lectura sobre el concepto de secularización, el filósofo Giacomo Marramao (1995; 1997) la describe como un proceso que marca el avance de la modernidad en todos sus aspectos: artes, ciencias, política, haciendo parte de la historia del pensamiento humano. Históricamente, el concepto tiene su origen en el derecho canónico, en su forma latina (saecularisatio: saecularis, saeculum), como vocablo surgido a partir de las últimas décadas del siglo XVI, en las controversias canónicas francesas, indicando el paso de un religioso "regular" a "secular" 3 . O bien, en general, como en otros estudios, referido a la "reducción a la vida laica de quien recibió órdenes religiosas o vive según la regla conventual" (Marramao, 1997, p. 17). Su uso se ha ampliado con el tiempo, siendo adaptado y reinterpretado a lo largo de los dos últimos siglos. Durante la Reforma, apareció como una metáfora en el marco legal refiriéndose a la expropiación de los bienes eclesiásticos en favor de los príncipes o iglesias reformadas.

Más tarde, fue apropiado por la filosofía, teología, historia, sociología y ética, en el sentido de descristianización. Comenzó a introducir la ruptura con los principios cristianos, sirviendo también como sinónimo de desacralización, abarcando tanto el mensaje cristiano como el anticristiano. Pero simplemente indica la ruptura con las instituciones religiosas (Ibídem, p. 17).

A partir del siglo XVIII, el vocablo secularización ha sobrepasado los límites de su aceptación legal para ser, entonces, una categoría genealógica, en general, "indisolublemente entrelazada con el nuevo concepto unitario del tiempo histórico". Fue adoptada por la sociología anglosajona y por la francesa, adquiriendo otras connotaciones simbólicas relacionadas a los problemas del desarrollo histórico de la sociedad occidental moderna como emancipación y progreso, liberación y revolución resultando en definiciones radicales y disoluciones de significados (Marramao, 1995, p. 29; 1997, p. 15; 1995, p. 23).

Para Marramao (1997, pp. 15-16), el concepto de secularización puede ser considerado un "ejemplo clamoroso de metamorfosis de un vocablo específico

3 Cf. Bobbio, Norberto et al. Dicionário de Política. Vol. 2. 5ª ed. Brasilia: UNB, 2000, p. 673, donde el término secularización difiere del término laicización por significar el regreso al mundo secular, sin haber renunciado totalmente al estado religioso. 
en una de las principales palabras-clave de la era contemporánea”, habiendo sido empleado para describir varias situaciones. Como consecuencia de este alcance, se ha convertido hoy en día en un término "un tanto difuso como indeterminado y controvertido".

Una interesante revisión bibliográfica acerca de la secularización fue presentada por Paulo Rivera (2001, p. 115), ampliando el entendimiento del empleo del vocablo. Según el autor, aparentemente lo radical "secular" es derivado del latín saeculum, lo que indica la duración de una generación (espacio de 100 años). En sentido figurado, es interpretado como "periodo indeterminado de duración de una vida, de una época o de aquello que se repite regularmente (como lo ordinario, lo mundano)". A partir de ese significado, la expresión se distingue de los votos monásticos, que determinan un distanciamiento del mundo. Para Pablo Rivera, la secularización es el proceso inverso a la sacralización; con todo, cuando se considera que en la modernidad occidental no hay Estado sagrado, tampoco hay qué secularizar.

La secularización también se puede utilizar para indicar la separación entre lo sagrado y lo profano. A pesar de las dificultades para distinguir con claridad ambos dominios, la secularización indica el declive de la religión, entendida aquí como la claridad de la iglesia sobre la sociedad medieval, que se presenta como consenso con los otros autores que pasan por la secularización. El autor también señala que los diccionarios indican "laico" como sinónimo de "secular", que también puede incurrir en algunos errores de interpretación. El término laico, por ejemplo, presenta un significado diferente tanto para el latín laicus como para el griego laikós. Si el primero se define en oposición a las órdenes sagradas o no vinculados a un sujeto, el segundo significa común u ordinario. En este sentido:

La secularización es su proceso que avanza invadiendo terreno de lo sagrado; "laico" puede ser aquello que jamás tuvo carácter sacro. Además, recuerde que en la Europa occidental medieval, lo sagrado era definido por la iglesia cristiana, que tenía el poder político para controlar a toda la sociedad. Aquellos que lograban escapar de ese control se colocaron en el "campo secular" (Rivera, 2001, pp. 116-117). 
Esta posición era vista como sinónimo de osadía. Así, él traduce el término secularización como "la fuga del control eclesial y de la heteronomía en pro del control político del Estado y del autocontrol”.

Pero un autor que participa del debate de la secularización es Demetrio Velasco (2006, pp. 15-16), que la describe como un fenómeno complejo que se refiere a procesos sociales distintos, que no deben confundirse entre sí. Ellos son: a) secularización como diferenciación y emancipación de las esferas seculares en referencia a las instituciones y normas religiosas; b) secularización como disminución de las creencias y prácticas religiosas, hasta su desaparición definitiva; y, finalmente, c) secularización como “marginalización” de la religión en el "ámbito privado”.

Demetrio Velasco explica que estos procesos pueden coexistir, pero varían de acuerdo con la realidad social. En varios países de Europa se producían simultáneamente y las teorías sociológicas dominantes afirmaban que todos estaban interligados. Sin embargo, al darse cuenta de que la secularización no se dio de la misma manera en todos los lugares, los sociólogos de la religión de origen norteamericano advirtieron que, dadas las diferencias, no había por qué continuar interpretando la secularización de esa manera. Esto llevó al autor a entender también el laicismo en sus diversos aspectos, como lo explicaremos mejor más adelante.

De esta forma, cada país tiene su proceso de secularización particular, así como su nivel de laicidad. Hay todo un ambiente, influenciado por los aspectos histórico- sociales que interfieren en cómo se produce el proceso de secularización, cuando se produce, en cada lugar. A pesar de todas estas advertencias, entendemos que el concepto de secularización tiene un eje central, del cual parte su sentido más general, interpretado básicamente por la autonomía de las distintas esferas de la vida social de la tutelada por la religión.

\section{EL ASPECTO POLÍTICO DE LA SECULARIZACIÓN: LA LAICIDAD}

Como se indicó, el proceso de secularización no se limita al campo institucional, no está restringido al debilitamiento del poder de la Iglesia ni al afloramiento de religiosidades individualizadas, pero tiene importantes consecuencias culturales. 
Aborda al terreno político en el campo de los derechos y en la delimitación del poder del Estado sobre las decisiones privadas. En el caso brasilero, como en otros países, se refiere al laicismo ${ }^{4}$, como a la pérdida del poder de la Iglesia católica. Fue de esta separación que resultó la libertad religiosa y el pluralismo religioso; pero hay que destacar que el laicismo no está siempre relacionado con estos aspectos. En Gran Bretaña y en los países escandinavos, por ejemplo, hay tolerancia religiosa sin laicidad. Como ocurre con la secularización, el proceso de laicización no es único, pero depende de cada circunstancia y varía en intensidad y alcance de un lugar a otro. Sin embargo, si por un lado, la separación de la Iglesia del Estado resulta en un proceso de privatización de la religión, por otro lado no se vuelve el responsable de su desaparición. La religión pierde su peso en la vida social, pero a nivel individual queda sujeta al libre albedrío de cada uno. Podemos entender, entonces, que cuando, en una de sus múltiples facetas, el proceso de secularización alcanza a la esfera política, recae en el fenómeno de laicización. El proceso de laicización sufre un impacto dominante de secularización que se instala en determinada sociedad.

Originalmente la expresión laico significando secular, del pueblo, en oposición a lo que es clerical (Velasco, 2006, p. 15). Al igual que la secularización, el laicismo se puede percibir como un aspecto positivo, a través de la creación de un Estado neutral, desvinculado de cualquier grupo religioso que pueda afectar a sus decisiones; pero también puede recibir una connotación negativa, de la exclusión de la religión del Estado y del ambiente público. Nestor da Costa (2006, p. 126) explica que laicidad es un concepto polisémico, que puede ser utilizado en varias circunstancias con significados o énfasis diferentes.

En algunos países, como en Uruguay, el laicismo se configura, según el autor, como "expresión concreta del proceso de secularización" con efectiva separación del universo religioso del Estado. Pero hay diferencia entre ese proceso en Francia, Estados Unidos,

4 Cf. Bobbio, Norberto et al. Diccionario de Política. vol. 2, 5a. ed. Brasilia: UNB, 2000, pp. 670-671. En esta obra de laicismo indica la diferencia entre el clero y el laicado, que ejerció influencia constante en la cultura política y en las instituciones públicas. El laicismo puede seguir en la dirección de una militancia. Añadimos a esta información que el término laicidad es más amplio ya que no solo se refiere únicamente a las formas jurídicas y políticas de organizar las relaciones entre la religión y la sociedad, pero con las formas de vivir y de pensar, lo que incluye el pluralismo, la convivencia con la diversidad. 
Espańa y en todos los países latinoamericanos, exclusivo de cada contexto. De esta manera, la laicización se constituye como una expresión singular de los procesos de secularización de las sociedades modernas, traducido en formas concretas de organizar las relaciones entre el Estado y la sociedad (Velasco, 2006, p. 29).

Con todo, cada escenario tiene su propio formato y ritmo. Al respecto, Paulo Rivera (2002, p. 95) considera que, inicialmente, laicización y secularización pueden ser consideradas como parte de un mismo movimiento, ya que ambos implican la "ruptura de la simbiosis entre la sociedad religiosa y la sociedad civil". Esta relación, sin embargo, es parcial, ya que toda sociedad comprende características comunes a cada una de esas condiciones, cada una de ellas evolucionando de diferente manera. Siendo así, será siempre posible decir que una sociedad no es secularizada ni laicizada, o al contrario de acuerdo con una determinada perspectiva. Entonces constituyen marcas de la contemporaneidad, presentes, de una forma u otra, en mayor o menor grado, en las distintas sociedades.

Para Roberto Blancarte (2006, pp. 150-151), sin embargo, la noción de laicidad no tiene por qué estar necesariamente asociada a la de separación de esferas o de separación jurídica entre lo político y lo religioso. Puede estar relacionada con la pluralidad religiosa y a la necesidad de una entidad suprarreligiosa en un Estado apoyado en una ciudadanía nacional. En su opinión, el elemento que permite entender la noción de laicidad es la legitimidad. Con ello, el autor indica aspectos de diversos contextos culturales para resaltar la importancia del derecho a la diferencia. A partir de esta argumentación, se puede concluir que la laicidad es un principio importante, principalmente en sociedades multiculturales, como una forma de alentar la tolerancia, lo que parece estar incluido, de cierta forma, también en el proyecto de secularización. La tolerancia está incluida en el campo de los derechos humanos, de libertad de expresión de pensamiento, lo que permite la convivencia pacífica entre diferentes tendencias.

\section{Secularización SUbJeTIVA: DESENCANTo O DESMAGiCACión}

Según Peter Berger (1985, p. 119), la secularización se puede percibir como la pérdida de poder y credibilidad de la institución religiosa en la sociedad moderna. 
Con este entendimiento, él lo define, en su forma más simple, de la siguiente manera: "el proceso por el cual sectores de la sociedad y de la cultura están extraídos de la dominación de las instituciones y símbolos religiosos" (Ibídem). Ese proceso se puede concretizar tanto en el ámbito individual, a través de la secularización de las conciencias, como a nivel de la sociedad, lo que resulta en el debilitamiento de las instituciones religiosas, de las cuales se desvincula el individuo. Surge a partir de entonces un movimiento de desinstitucionalización o, incluso, de ausencia de pertenencia religiosa, que entra en el epicentro del debate sociológico.

Berger (1985, p. 118), explica que en cuanto al concepto ideológico, el término secularización adquiere connotaciones valorativas, algunas positivas y otros negativas. En los círculos anticlericales se ha liberado de la tutela de la religión, sin embargo, en aquellos vinculados a las iglesias tradicionales ha sido combatido por haber adquirido el sentido de descristianización. O sea, para aquellos que consideran que la religión limita al individuo, lo aliena, según Karl Marx, secularización significa liberación. Para los que consideran la religión como un pilar, fuente de explicación para la vida del individuo, la secularización se vuelve como un camino nocivo. Las dos acepciones, con valores opuestos, componen así el mismo fenómeno empírico.

Según Peter Berger (1985, pp. 118-119), debido a las diferentes interpretaciones y aplicaciones, ya fue sugerido el abandono del término secularización, que se volvió confuso. Sin embargo, se opone a esta propuesta, ya que, para él "el término secularización se refiere a procesos disponibles empíricamente de gran importancia en la historia occidental moderna". Una de las mayores contribuciones de la secularización para gran parte de los países occidentales, principalmente iberoamericanos y del sur europeo, es la libertad religiosa y el pluralismo religioso.

Fue basado en la observación del crecimiento del pluralismo religioso en la sociedad norteamericana, que Berger (Ibídem, p. 149) elaboró su definición de mercado religioso. Con la prohibición de la oficialización de una religión en detrimento de otras se instaló una situación plural, transformando instituciones religiosas en "agencias de mercados y las tradiciones religiosas se convierten en bienes de consumo". Esta situación tendrá, según el autor, consecuencias a largo plazo para la estructura de los 
diversos grupos, generando una competencia entre ellos y propiciando estrategias para atraer adeptos, lo que garantizará la sobrevivencia de las instituciones.

Para Berger (Ibídem, pp. 119-120), "el Occidente moderno ha producido un creciente número de individuos que enfrentan el mundo y sus propias vidas sin la utilización de interpretaciones religiosas". Muchos de ellos no quieren, o mejor, no sienten la necesidad de instrumentos religiosos para orientar sus vidas o su comportamiento en sociedad. Son las mentalidades secularizadas que se reproducen actualmente. Aunque el individuo reciba influencias de su medio, la secularización de una conciencia individual no está directamente vinculada a la vertiente social (Berger, 2001, p. 10). Eso quiere decir que no hay necesariamente simultaneidad entre la secularización objetiva y la subjetiva.

Conviene resaltar que este proceso de secularización es percibido de manera diferente por los autores. Algunos de ellos, como Antonio Flávio Pierucci, dicen que, para Max Weber, el proceso de secularización no corresponde al sentido de desencantamiento del mundo, que está inmerso en el proceso de modernización, de racionalización, teniendo entonces, una duración histórica mayor que la secularización. En ese sentido, Pierucci (2000, p. 121) sugiere que la secularización puede ser interpretada como una "conclusión lógica del proceso histórico-religioso de desencantamiento del mundo".

Mientras que el primero se percibe como un proceso esencialmente religioso, refiriéndose a la eliminación de la magia como un instrumento de salvación, pudiendo resultar en el fin de la religión; el segundo se refiere a la decadencia de la religión en la cultura moderna. En su amplitud, el desencantamiento se relaciona con la ciencia y su potencial transformador en la modernidad, concediéndole un nuevo sentido al todo. O sea, se da un proceso de desmagnificación, desencadenado por la introducción de la religión ética y además, por el desarrollo científico y tecnológico.

En una revisión más completa del concepto en la obra de Max Weber, Pierucci (2003, p. 120) detalló ambos, concluyendo que la secularización weberiana se refiere a la diferenciación, separación y emancipación del ámbito de la religión de las esferas política, económica y social, de la substracción o retracción del status religioso 
en el mundo (Ibídem, p. 57). El desencanto del mundo5, a su vez, que debe ser comprendido técnicamente, "no significa una pérdida para la religión ni una pérdida de religión, como secularización”.

Después de evaluar el texto sobre la situación de la religión en China, entre otros, Pierucci (Ibídem, pp. 132-133) concluye que, para Weber, la magia se presenta como un obstáculo en el desarrollo, obstáculo al racionalismo. Por consiguiente, el "desencanto es desobstaculización, libertad, liberación". Sin embargo, hay sutilezas, ya que no se trata de una guerra contra la magia en general, sinónimo de inercia ritualista, mirándola como un obstáculo a la racionalización de las relaciones sociales. Es el choque de la religión eticidada con la magia sacramental como medio técnico de la salvación, resultando en la pérdida del terreno de la magia para la religión.

Es una forma a través de la cual los individuos dejan de apelar a la magia y al cosmos sagrado para explicar el mundo, abriendo espacio para las verdades comprobadas por la ciencia, con la razón. Así, Pierucci explica que el desencanto del mundo debe ser entendido en Weber como desmagificación.

Es importante resaltar que este proceso de desmagificación, en Weber, tiene su inicio en algunas formaciones religiosas, con un papel fundamental en la expansión de la racionalización ${ }^{6}$. Sin embargo, el mundo moderno no está totalmente desencantado. Recuperando la obra de Weber, nos encontramos con lo siguiente:

El destino de nuestro tiempo, que se caracteriza por la racionalización, la intelectualización y sobre todo, por el desencanto del mundo, llevó a los hombres a prescindir de la vida pública los valores supremos y más sublimes. Tales valores encontraron refugio en la trascendencia de la vida mística o en la fraternidad de las relaciones directas y recíprocas entre individuos aislados (Weber, 1972, p. 51).

5 Según el autor Entzauberung der Welt en los términos de Weber.

6 Por racionalización se entiende la organización de la vida en sectores de actividades, considerando las relaciones humanas y sus instrumentos con el fin de alcanzar la eficacia y el rendimiento. 
A través de este pasaje vemos, por un lado, que si Weber quita la magia, en su forma más primitiva, del espacio reservado a la vida pública, por otra parte, el no parece descartar la posibilidad de una relación individual con lo sagrado. Es lo que, entre otros autores, Pierucci explicará más adelante a través del debilitamiento de la religión en la vida social, pero "no necesariamente su desaparición de las mentalidades individuales". Por ello, tenemos de este autor, un eventual florecimiento de la religiosidad, lo que será tratado más adelante, no indicaría “automáticamente el concepto de reencantamiento, ya que desencantamiento en Weber significa un triunfo de la racionalización religiosa”.

Esa racionalización no se dirige obligatoriamente hacia el fin de la religión, sino hacia la transformación de sus relaciones en la sociedad. En un contexto racional, de diferenciación técnica y especialización científica como este, los intelectuales parecen desempeñar un papel importante, contribuyendo a la estabilidad de la ciencia y a la difusión del conocimiento.

\section{LA HIPÓTESIS DE LA SECULARIZACIÓN TAMBIÉN CUESTIONADA}

Durante mucho tiempo la secularización fue presentada, por algunos autores, como una canalización irresistible para la historia de la humanidad, eliminando la religión de su escenario. Berger apoyaba esa discusión hasta que la observación de los acontecimientos diarios le mostraron otro camino: la religión no parecía haber desaparecido totalmente de la sociedad según lo pronosticado por algunos autores. Esa verificación repercutió en su producción, resultando en una propuesta polémica de desecularización, resaltando las equivocaciones en la teoría de la secularización.

Esa revisión se dio cuando Berger se encontró, entre otros eventos de la religión contemporánea, con el fundamentalismo, llegando a apodar a una de las obras que consultaba como "libro bomba". Redactó un artículo, explicando que si algunas instituciones perdieran su poder e influencia en algunas sociedades, en otras eso no sucedería. Las prácticas religiosas antiguas o nuevas subsistieron, en sus variadas formas, algunas veces hasta llegar inclusive a "grandes explosiones de fervor religioso". 
Por otra parte, las instituciones religiosas pasaron a desempeñar un papel social o político, aun con pocos miembros, lo que complica el panorama (Berger, 2001, p. 9).

Este cuadro es aún peor cuando el autor se da cuenta de que las instituciones religiosas y los movimientos que buscaban adaptarse a la modernidad han disminuido, mientras que los otros, conservadores, ortodoxos, crecían ${ }^{7}$. Así, Berger constató que la modernidad no parecía haber declarado la desaparición de la religión, lo que mostró que, salvo en algunas excepciones, la vieja teoría de la secularización valía en algunos lugares con algunos tipos, pero no era válida para otros.

Aparentemente, los únicos inmunes a la tesis de la de secularización sería Europa Occidental y personas con alta escolaridad, integrantes de una "subcultura internacional", principal portador de creencias y valores progresistas (Ibídem, p. 16). Entonces, lo que parece ocurrir de hecho, en ese escenario interrelacionado, donde lo local se diluye en lo global lleno de incertidumbres, es un cambio en el lugar institucional de la religión y de ahí la "interacción de fuerzas secularizantes y contrasecularizantes" (Ibídem, p. 14).

En esa misma dirección, Stéfano Martelli (1995, p. 411), en sus investigaciones sobre la religiosidad en Italia, también resalta que "la religión no es, de hecho, la parte residual de la sociedad, mecánicamente compleja con los vínculos de la comunidad, al punto de retraerse frente al avance del proceso de racionalización”. La religión fluctúa en la sociedad contemporánea; así, al lado de señales de secularización se encuentran también señales de desecularización. Conviven, por ejemplo, universos tradicionales religiosos con nuevas formas religiosas, que tienen como telón de fondo un alto grado de libertades individuales. El surgimiento de elementos religiosos demuestra esa rotación entre los polos secular y el no-secular, sugiriendo que no hay una racionalización irreversible del mundo.

7 En medio de tantas transformaciones, Berger (2001, pp. 14-15) destacó dos movimientos religiosos evidentes en la actualidad: el movimiento político-religioso del islamismo y el creciente de los evangélicos, con sus estrategias frenéticas de conversión en masa, ambos presentes aun en los sectores más modernos de la sociedad. En el caso del islamismo, está presente también entre las clases sociales más intelectuales. 
A pesar de algunas coincidencias, el pensamiento de Peter Berger ha sido criticado en Brasil por algunos científicos sociales. Entre aquellos que más nos llamaron la atención, Cecília Mariz (2001, p. 27), al revisar su propuesta conceptual, se observa una contradicción en el concepto de desecularización. La autora argumenta que si Peter Berger resalta en varios pasajes que la decadencia de la religión no fue observada, de hecho no se habría llevado a cabo un proceso de secularización; "por lo tanto, se podría cuestionar la pertinencia del concepto de "desecularización"”. Si no hubo, así, secularización, no podría haber habido desecularización. Esa discusión recibe otro enrutamiento a través de Pierucci (2000, pp. 108-109), alegando que lo que Peter Berger llama como desecularización también puede ser entendido como possecularización.

Para Pierucci (Ibídem), ese "post” surge como una alusión a la llamada sociedad possecular, posindustrial, posmaterialista, poscomunista, posmoderna, como si el mundo contemporáneo abriese un nuevo espacio para el abandono de la hipótesis de la secularización y también para la asociación de la secularización con la modernización. Pierucci refuerza que los conceptos de secularización y desecularización no son aceptados de la misma manera por la intelectualidad, ya que algunos no creen que haya sucedido en muchos lugares ningún proceso de secularización ni de desencanto del mundo, no habiendo, por lo tanto, desecularización.

En sintonía con las teorías que exaltan las grandes transformaciones de la modernidad, más precisamente, posmodernidad, Zygmunt Bauman (1998, pp. 205-206) también destacó la presencia del fundamentalismo o integrismo como un interesante ejemplo de modificación de estas etapas. Para Bauman (1998, p. 226), el cuestionamiento sobre Dios y la religión ya fue hecho; ahora aparecen "soluciones" para los problemas más genuinos de la vida de los individuos posmodernos, como el fundamentalismo. Surgió una forma moderna de religión, incluyendo las contradicciones intrínsecas de la vida moderna.

El integrismo y el fundamentalismo que surgen esporádicamente, por ejemplo, son muy parecidos con lo que el denomina "reavivamientos étnicos". Bauman considera que estas formas constituyen un fenómeno totalmente contemporáneo o posmoderno, que utiliza todos los recursos racionales proporcionados por la 
modernidad para presentar los remedios específicos para los males que se presentan en ese nuevo escenario. Los fundamentalistas se establecen, principalmente, con la promesa de emancipar a los conversos de las agonías de la elección y brindar seguridad en un mundo incierto. Por lo tanto, "es una oferta de racionalidad alternativa, hecha sobre medida para los problemas genuinos que asedian a los miembros de la sociedad posmoderna" (Bauman, 1998, p. 229). Si por un lado, el fundamentalismo presenta la racionalidad del mercado, seleccionando, dividiendo; por el otro difiere de ella al colocar la seguridad y la veracidad en primer lugar, condenando las "extravagancias de la libertad individual”.

Para Bauman es esa la diferencia que hace que él crezca, ya que la interpretación fundamentalista de la religión es personal, tan privada como cualquier otra opción que puede ser sopesada para algunos más que para otros. En ese sentido, en un mundo altamente cambiante, inestable, los fundamentalistas se establecen, construyendo un puerto seguro que algunos individuos buscan. Ellos ofrecen otro lenguaje, mas allá del mensaje sobre la carencia y la debilidad humana que por tanto tiempo alimentó las instituciones tradicionales. Según Bauman (Ibídem, p. 224): “ya no son las organizaciones religiosas, con su mensaje de la perpetua carencia del hombre, que son mejor adaptadas a la comunicación de la experiencia máxima a quien no logra lo máximo". Si en la rutina diaria ya no había espacio para incluir inquietudes sobre los límites de las cosas, la revolución moderna redujo todavía más el tiempo que podría ser destinado a eso y forzó una adaptación racional a condiciones de vida totalmente nuevas. En ese contexto, "había poca utilidad para la religión” (Ibídem).

Inicialmente, las transformaciones en las condiciones y estrategias de vida viables generan lo que él llamó de "descristianización", reduciendo el espacio de la religión dominante (en el sentido de instituciones tradicionales) que, encerrada en su estructura rígida, no se preparó para comprender la nueva situación y enfrentar los nuevos desafíos. Para mantenerse, iglesias y sectas necesitan ocuparse de otras tareas más prácticas, además de los misterios de existencia.

Desde esta perspectiva, el fundamentalismo o integrismo se establece en la posmodernidad, atrayendo aquella clientela más susceptible a sus llamados, aquella marcada, según el autor, por la "miseria de la vida compuesta por elecciones 
arriesgadas", responsabilidades desconocidas, inseguridades y sus consecuencias, para las cuales el individuo no puede estar preparado (Bauman, 1998, p. 227). El mensaje que queda de esa experiencia es que, dado el fracaso del individuo, el no puede ser autosuficiente y necesita ser guiado, informado de lo que debe hacer. De esta manera, el fundamentalismo trae al público la subterránea ansiedad de la condición posmoderna, conduciendo a aquellos que necesitan de su apoyo.

Danièle Hervieu-Léger (1997, pp. 72-73), tal como Bauman, también comenta sobre el integrismo, reportándolo a la contemporaneidad, como "la otra cara de la escena religiosa contemporánea". La autora lo presenta como un fenómeno combinado con la dinámica de la individualización de las creencias, refiriéndose tanto al escenario europeo como al latinoamericano. En su argumentación, ella demuestra que integrismo e individualización son movimientos interconectados, enumerando tres posiciones. Ellas son: a) Cuando se individualiza el modo de creer; se torna más homogéneo (desregularización institucional de la creencia); b) cuanto más homogéneo se vuelve el modo de creer, más se acelera la circulación de los creyentes y, finalmente, c) cuanto más se acelera la circulación de los creyentes, más se refuerzan las presiones de las comunidades.

La primera proposición, para la autora, no trae como consecuencia la fragmentación de los pequeños sistemas de creencias producidos por los individuos, pero sí una liberación del mercado de bienes simbólicos. En este los grandes inversores institucionales (las iglesias) ya no son los únicos que manejan el juego. Como consecuencia de ello hay una homogeneización de los pequeños sistemas creyentes en un contexto globalizado. Aunque parezca problemático recorrer las categorías de la economía para pensar el fenómeno religioso, su uso en un sentido analógico puede contribuir. De esta manera, la autora percibe lo que llama de "estandarización” de la producción simbólica como método de producción resultante de la liberalización del comercio, siendo posible gracias a la pérdida del monopolio religioso.

Danièle Hervieu-Léger se refiere, específicamente, en el caso de América Latina, con la proliferación de los grupos carismáticos católicos y evangélicos pentecostales,

8 Traducción libre. 
que presentan una religiosidad emocional reivindicando la reducción de la actividad intelectual y valorizando la experiencia afectiva de la presencia del Espíritu Santo. Ella explica que la relación en estos grupos se construye a partir de lo que llama "minimalismo teológico". Los fieles se adhieren a un mínimo credo (Dios te ama, Jesús salva, etc.), que no requiere explicaciones teológicas y cuya eficacia práctica se experimenta personalmente por cada creyente.

Según la autora esta es una forma que "permite la adaptación de los contenidos a las exigencias del individualismo moderno, en términos de expansión de sí mismo y de realización personal" (p. 73). Desde esta perspectiva, la fe como operador de un deber individual se presenta como el motivo central de la religiosidad moderna, presente en muchos movimientos. Hay entonces, un “credo común cuyo contenido teológico propio disminuye al mismo tiempo en que se muestran los beneficios personales singulares que cada uno recibe". En este panorama actual se evidencia una fluidez en la oferta que, según la autora, permite que los "buscadores de sentido" encuentren variantes temáticas asociadas a las demandas típicamente modernas, referidas al derecho de toda persona a la realización de su subjetividad.

La segunda propuesta, a su vez, es: cuanto más circulan las creencias, menos determinan y menos responden a objetos concretos. Es más, favorecen, al mismo tiempo, una aspiración comunitaria. Esto puede evolucionar hacia formas sectarias.

La tercera indica que la aceleración extrema de la rotación de las creencias, sobre todo a través de los medios de comunicación en masa, lleva al límite de desarticulación. Aquí Danièle Hervieu-Léger (2007, pp. 74-75) explica que "las elecciones de creencias por los individuos están cada vez más disociadas de los procesos de socialización que garantizan la inserción de los individuos en grupos concretos". La autovalidación de la creencia ya se sustenta por referencias mínimas que pueden ser compartidas en escala planetaria (refiriéndose a la interacción virtual). Son lecturas, actividades culturales, sitios web, etc., una serie de contenidos que se pueden consumir en dosis mínimas por muchos individuos. Así son construidas redes fluidas, móviles, de buscadores cada vez más virtuales - para ella, "grado cero dentro de un proceso de reintegración comunitaria espiritual”-, donde la validación está dentro del ámbito de las experiencias individuales. 
Con todo, Danièle Hervieu-Léger advierte que ese tipo de redes no se encuentran simplemente entre los seguidores de la "nebulosa Nueva Era", como a menudo se supone, sino también dentro de las religiones establecidas, trabajando al margen suyo o en el corazón de ellas, ya que existe una paradoja en la modernidad, marcado por la "extrema fluidificación del creer", donde los individuos se liberan de las grandes instituciones religiosas, construyen identidades diferenciadas, en la incertidumbre. Cuando no se presenta ninguna verdad y cuando toda la carga de hacer su propia verdad es atribuida al propio individuo, este debe disponerse, debido al alto costo social y psicológico de esto, de un acceso suficiente a recursos simbólicos que contribuyan a la construcción del sentido personal. La falta de elementos para validar la creencia facilita la adhesión a otras estructuras, otras formas de vida religiosa comunitaria, donde el individuo puede encontrar seguridad y dar su testimonio (Hervieu-Léger, 2007, p. 75).

De esta forma es que el individuo concreta el desplazamiento de los lazos socioreligiosos concretos. Se trata de una personalización que disuelve las identidades, produciendo la activación o la invención de pequeñas identidades comunitarias compensatorias. En sus extremos estos cambios podrían resultar en el integralismos, asociando certezas compartidas con las formas comunes de la organización de la vida cotidiana y la acción en el mundo.

Finalmente, Danièle Hervieu-Léger (1997, pp. 76-77; 1999, p. 196) enumera varios indicadores de una tendencia general a la erosión de los regímenes institucionales de validación del creer religioso en América Latina y en Europa. Entre ellos se destaca: el desarrollo de una religión a la carte, pérdida de fuerza de la observación, la proliferación de creencias creadas artesanalmente, la diversificación de las trayectorias de identificación religiosa, la amplia circulación de frentes, la permeabilidad creciente de fronteras denominacionales.

Es un proceso que se confunde con la propia modernidad contemporánea, que atraviesa por una crisis peculiar. De acuerdo con otros autores, para Danièle HervieuLéger la contemporaneidad está ambientada en un escenario de inestabilidad, que encarna este estado de diferentes creencias. Con los lazos aflojados de los grupos tradicionales, el individuo se distancia de ellos e intenta construir su propia identidad. En ciertos casos, se asocia a grupos fundamentalistas o integristas; en otros, busca 
sentido moviéndose entre otros grupos, o, inclusive, distanciándose de ellos, como nuestro objetivo: los sin religión.

$\mathrm{Al}$ observar la sociedad por el ángulo de la proliferación de creencias, Flávio Pierucci (1997, p. 104) se pregunta si estaría ocurriendo una invasión de lo sagrado, como indicativo de la posible recuperación de la fuerza de la religión. Sin embargo, es necesario observar que esas explosiones son más puntuales que generales, y que se dan más en el ámbito privado que en el público, lo que confirma, de cierta forma, el debilitamiento de la religión en la vida social, aunque, no necesariamente su desaparición de las mentalidades individuales.

A pesar de la multiplicación y reavivamiento de grupos religiosos en el tercer mundo, de acuerdo con el autor, hay una tendencia a la secularización. Aunque algunos Estados hayan vuelto a ser religiosos, esas experiencias son puntuales, lo cual ocurre solo en ciertos lugares. Con esto, el mundo actual, donde se destaca cada vez más que la ciencia tiende a ser más secular. El surgimiento esporádico de nuevos grupos o movimientos religiosos, por ello, hace parte del proceso de secularización. Según Pìrucci (1997, p. 111), estas oscilaciones son normales y necesarias para la vitalidad del sistema cuando un periodo de intensa movilización religiosa es sucedido por otro de desinterés, muchas veces por decepción con la vida religiosa, como una pausa necesaria para que el individuo se ocupe más de su vida íntima. En ese sentido, el debilitamiento de las tradiciones resulta en una multiplicación de ofertas religiosas y aún mas, en "el declive del compromiso religioso".

Si retomamos las teorías del mercado para comentar esas transformaciones, encontramos, en Peter Berger, la religión posicionada más como un bien de consumo en una sociedad plural al alcance de cualquier individuo que lo desee, lo que Pierucci (1997, p. 111) llama como "secularización omnívora". En esta sociedad, las ofertas y demandas son ajustadas en una balanza, en la cual también pesa la debilidad en los lazos que vinculan el individuo a la religión. Si en el ambiente cultural actual, las estructuras religiosas pueden convivir y competir en un clima de cierta tolerancia, es porque hay un procesos de secularización, que modifica la relación con lo sagrado. Este cambio también puede se interpretado, más que como un proceso de desmagificación o desacralización, como un proceso de destradicionalización. 


\section{El DEBILITAMIENTO DE LAS RELIGIONES TRADICIONALES}

Al mostrar, en Brasil, la declinación de las religiones más tradicionales como el catolicismo, el luteranismo y el umbanda ${ }^{10}$, Pierucci (2004, pp. 18-19) se pregunta si ese es un proceso internacional. Y así recuerda lo que viene ocurriendo con el hinduismo, que pierde terreno con la expansión musulmana en la India, "así como el catolicismo brasilero pierde terreno con el avance pentecostal”.

Eso demarca cambios profundos en la constitución de nuestra sociedad, a los cuales él se refiere como Bye Bye Brasil tradicional. Se trata de una transición religiosa de la cual los evangélicos y los sin religión aparecen como sus principales beneficiarios. Para Pierucci, eso ocurre porque en las "sociedades postradicionales" ocurre un proceso de desafiliación religiosa, desencadenado por el abandono de creencias y pertenencias que se vuelven opcionales. Ese proceso refleja la tendencia de los individuos a apartarse de los lazos tradicionales, lo que termina por debilitar ciertas instituciones religiosas. Hay toda una dificultad de establecer vínculos, lo que parece una marca registrada de la sociedad contemporánea, fluida, globalizada, racionalizada y extremadamente individualizada o, más precisamente, privatizada.

Esa marca también sobresale cuando Pierucci (2006) presenta la religión universal como solvente de lazos consolidados como aquellos de las conocidas religiones étnicas (en este caso las religiones afrobrasileras, que eran consideradas así) y el adviento de la religión universalizante. En ese texto, él se opone a la perspectiva de Durkheim, mostrando en la actualidad la capacidad corrosiva de una religión, lo que inspira su título "Religión como solvente", que lejos de vincular nuevamente al individuo a la sociedad a la cual pertenece, es capaz de disolver vínculos tradicionales. Eso es demostrado, por ejemplo, por el impulso con que los evangélicos ganan terreno en detrimento de los cultos afrobrasileros, destacando, una vez más, la fragilizacion del umbanda, una religión típicamente brasilera, considerada una "forma religiosa plenamente ajustada" a su realidad (Pierucci, 2006, p. 113). Así, él se refiere, sobretodo, a la falta de aliento de las religiones tradicionales para la reproducción,

9 Protestantismo de inmigración, la primera de las formaciones del protestantismo.

10 Por su naturaleza sincrética, puede ser considerada una "religión brasilera por excelencia". 
dando como resultado lo que él describe como el "adiós al sincretismo" -una referencia obvia a la situación del umbanda $-{ }^{11}$.

Entonces Pierucci (Ibídem, p. 120) comenta la tendencia universalizante del protestantismo, tradicionalmente una religión de conversión que gana cada vez más adeptos, da menos valor a la "herencia religiosa o linaje de fe" que al ingreso voluntario a una congragación. Es una religión congregacional de salvación, desvinculada de lazos sanguíneos, instituida de una lógica individualizante implacable, lo que la distancia del punto de vista durkheimiano, mostrando que ese no se aplica a las transformaciones de la contemporaneidad. Es cuando el individuo atiende a un llamado externo, insertándose en una nueva vida comunitaria, buscada y escogida por el "individuo individualizado". Es por eso una religión "corruptora, efectivamente destructiva” (Ibídem, p. 122).

Para Pierucci, la religión de salvación solo se establece por "vía de extracción”. Ella "extrae sistemáticamente los miembros de otras colectividades" [...] "destaca partes y desata nudos, despedaza relaciones sociales heredadas y desmiembra colectividades ya distribuidas". De esa forma, esa modalidad de religión constituye una asociación de individuos que disgregó y atomizó a aquellos que en ella se empeñan individualmente. Diferente de la religión totémica, la congregacional no constituye, por lo tanto, una comunidad de individuos, en los moldes de Durkheim, pero sí una comunidad tal cual en la propuesta de Weber. Ella se fundó en la competición entre los lazos de los hermanos de fe y los hermanos de sangre (Ibídem, p. 123). Funciona, así, principalmente como solvente de antiguos lazos y no como refuerzo de la estabilidad de la sociedad.

Según el autor (Ibídem, pp. 124-125), en la perspectiva weberiana, no hay interés sobre la religión que celebra una comunidad vigente, pero sí sobre la que inventa, aunque tenga que cortar otras relaciones, "desarmando la continuidad de

11 A lo largo del artículo sobre la universalización de ciertas religiones que ya fueron clasificadas funcionalmente como étnicas, Pierucci se apoya en los censos para demostrar el proceso de "blanqueamiento" de los seguidores de los cultos afrobrasileros y la predominancia de los negros entre los evangélicos convertidos (Pierucci, 2006, p. 118). 
la antigua geografía de las comunidades constituidas". Es la sobreposición de la religión individual a la colectiva, como "ruptura individualizante de lazos otrora consolidados", configurándose como lo opuesto de la religión que impresionó a Durkheim, asociada a la cohesión de un grupo.

Entonces, en el lugar de la comunidad solidaria constituida por representaciones colectivas aparece la red difusa y privada, de centro, conocida como afiliaciones genéricas, que sustituyen la comunidad por la humanidad. La fuerza moral de la religión brasilera, según Pierucci, está en su capacidad estadísticamente comprobada de disolver antiguas pertenencias y lapidar linajes religiosos establecidos, como en el caso de Bye Bye Brasil.

Esa religión universal de salvación, de redención, es la que tiende a predominar sobre las demás, desconectando a las personas de su cultura. Ella "desestabiliza y exilia". Por lo tanto, la destradicionalizacion cultural -en los términos de Pierucci- abre espacio para el ejercicio de una nueva religiosidad, más íntima, menos compartida. En esa perspectiva, el individuo se reserva el derecho de buscar los bienes religiosos que le interesan sin, a pesar de ello, sentirse obligado a afiliarse a una sociedad religiosa, una iglesia, o inclusive compartir su creencia con quien quiera que sea, como ocurre con muchos individuos sin religión.

El individuo puede hacer eso en su propio aislamiento mental. Según Pierucci (2006), la perspectiva de una religión durkheimniana, practicada en sociedad, pierde fuerza en la actualidad. El individuo, mirándose a sí mismo y su búsqueda anterior, descubre una nueva forma de relacionarse con lo que lo trasciende, sin necesidad de manifestar en público su fe o establecerse en un solo credo, pudiendo circular como un peregrino.

Danièle Hervieu-Léger dice que fluidez y movilidad son las palabras clave del mundo moderno, ambiente donde se sitúa el peregrino, de cambios sociales que avalan las habilidades colectivas en el establecimiento de ideas; que están en crisis debido al debilitamiento de los lazos sociales. Sin embargo, eso no comprueba las teorías de la secularización, ya que, según al autora, "no es el fin sino la metamorfosis de la religión” en sus formas tradicionales (Hervieu-Léger, 2000, p. 25). 
En ese contexto, la ciencia no puede asumir las funciones de la religión, que queda por fuera del "reino del conocimiento" 12 . No hay respuestas infalibles para los asuntos recurrentes sobre la naturaleza humana y su lugar en el Universo; y no hay cómo esclarecer los asuntos morales que confrontan al individuo con la comunidad. Además, la ciencia no puede responder a la necesidad de rituales inherentes a la sociedad. Por lo tanto, no hay sustitución de la religión por la ciencia. Por lo tanto, "si la religión dejó de ser el lenguaje descalificado de la experiencia humana, ella continúa siendo un elemento vital en la sociedad moderna" (Ibídem, p. 26). Con eso, es mostrado que lo que hay, en la actualidad, es una transformación evidente, bajo diferentes formas y en diferentes lugares. Hay una religión que está marcada por la destradicionalizacion y desinstitucionalización, lo que plantea otro tipo de rumbo de la cuestión.

Para Hervieu-Léger (Ibídem, pp. 167-168), el verdadero debate para la sociología está relacionado con las "consecuencias para las instituciones tradicionales de las religiones de la radical desinstitucionalización de lo religioso". No se trata solamente de una discordancia con el ambiente secular, que tiende a marginar las influencias de la religión. Menos aún, de saber si su pérdida de influencia es el resultado de la ansiedad o la renuencia a hacer concesiones a la cultura moderna. Para la autora, el problema real en lo que se refiere al futuro -tal vez a la sobrevivenciade las instituciones religiosas tradicionales, está relacionado con su habilidad para contemplar la "naturaleza flexible de las creencias cuando son afectadas" de acuerdo a la nueva dinámica, donde reside una "negación del modelo tradicional de administrar la memoria autorizada” (Ibídem, p. 168).

Frente a un sinnúmero de registros empíricos, la autora constata que no hay incompatibilidad entre modernidad y religión, sino una necesidad de reformulación de esa interpretación en el campo teórico acerca del panorama de la secularización y de la racionalización en el mundo occidental. El debilitamiento de las instituciones religiosas tradicionales $-\mathrm{y}$ solamente de ellas ${ }^{13}$ - es una característica de

12 Traducción libre.

13 Conviene resaltar, todavía, que aun dentro de los grupos que decaen, sobre la amenaza de desaparecer, hay una capacidad de cambio que reside en la memoria colectiva, responsable por transmitir y así preservar la tradición. 
contemporaneidad, pero eso está acompañado de la expansión de otras formas de religiosidad que parecen más interesantes.

Una reflexión importante acerca de algunos de esos grupos que se expanden se encuentra en otro artículo (Hervieu-Léger, 1997), también presentando cambios evidentes en el patrón de religiosidad de las sociedades occidentales contemporáneas. En ese texto, la autora reafirma la vitalidad de la religión a través de la expansión de las comunidades emocionales, marcadas por lazos de afecto y por la "repulsión a una religión intelectual”, entre otros, además de cierta inestabilidad peculiar del grupo. Esas comunidades, fragmentarias, que se expanden en la actualidad, apuntan hacia la recomposición del papel de la religión en la sociedad contemporánea. Sintonizadas con su tiempo. Ellas pueden ser interpretadas a la luz de una relación ambivalente entre tendencias desecularizantes y tendencias secularizantes, que siguen juntas en las “experiencias de renovación emocional". Lo que parece contradictorio con el proceso de secularización (Hervieu-Léger, 1997, p. 44).

Esas comunidades reflejan la desregulación de lo religioso institucional tradicional, ya que el individuo deja las doctrinas formalizadas para aventurarse en diversas experiencias místicas que le dan el sentido y la eficacia que busca. Son algunas de las nuevas formaciones de la contemporaneidad, que cuestionan la religión institucional tradicional, valorizando opciones subjetivas, racionales, individuales y emocionales (Ibídem, p. 44). Se percibe, entonces, que a pesar del instrumento de racionalidad vigente, no desaparece la necesidad de significados e identidad que el individuo buscaba en la religión tradicional. El debilitamiento de las plausibilidades tradicionales, usando las palabras de Peter Berger, no impide, por lo tanto, que el individuo siga en su búsqueda individual de sentido, estableciendo una relación diferente con lo trascendente. Siendo así, este "emocionalismo antimoderno constituía así y paradójicamente, un modo de adaptación de las religiones al mundo moderno" (Ibídem).

El diagnóstico de Danièle Hervieu-Léger (Ibídem, pp. 32-33) sobre el panorama del siglo XXI indica que hay una reivindicación de sentido por las sociedades occidentales, perturbadas por la crisis internacional, demandando la vuelta de lo sagrado en pro de algún equilibrio y seguridad. Surge, entonces, en las sociedades conocidas como secularizadas, una nueva religiosidad marcada por el surgimiento 
de comunidades emocionales que se reúnen para la práctica de rituales religiosos. Aflora, a partir de ahí, el éxtasis, las manifestaciones efusivas de sentimientos, de misticismo, la proximidad del contacto, lo que la autora clasifica como "religiosidad caliente" en contraposición a una "religión intelectual". Se trata de un reavivamiento espiritual que indica que, en sintonía con el "espíritu de nuestra época", oscilan ondas de secularización y desecularización. Por consiguiente, esos grupos contemporáneos también fluctúan entre la modernidad y la antimodernidad (1997, pp. 32-44), una relación ambivalente que marca, sobre todo, los nuevos movimientos religiosos. En ese contexto, la religión se constituye apenas como una dimensión de la vida personal.

\section{CONSIDERACIONES FINALES}

Frente a este panorama, se observa que, sobre el paraguas de la secularización pueden estar abarcados no solo el fin del monopolio religioso, sino también la privatización de lo simbólico, que pierde su alcance como contenido universal. Emerge, entonces, el refuerzo del individualismo a través de la abdicación de la identidad religiosa colectiva en pro del ejercicio de la religiosidad individual. Eso además del refuerzo del pluralismo religioso, estimulado principalmente por la propuesta de laicización del Estado. Concluimos que, si hasta entonces se asociaba secularización con modernidad, resultando inevitablemente en la desaparición de lo religioso; posteriormente se concluye que las dos cosas no estaban automáticamente interligadas. Lo religioso entró apenas en proceso de transformación, de adaptación a las nuevas condiciones coyunturales y subjetivas; se trata de un desplazamiento de su lugar de lo social para lo privado y de este para lo íntimo. Tenemos, entonces, la religión como una cuestión de foro íntimo que nos permite comprender la identificación de individuos que se declaran sin religión en el mundo contemporáneo, no solamente en la sociedad brasilera, sino también a nivel internacional.

El alarde sobre el crecimiento de los sin religión en Brasil, destacándose su presencia marcante en el Estado de Río de Janeiro, fue hecho inicialmente, a través de la publicación de los resultados de los últimos censos demográficos, sirviendo de base para las distintas investigaciones. Las categorías del censo son proyectadas en las porciones del espacio geográfico, asignadas, siendo entonces, organizadas desde su 
situación demográfica, las condiciones de producción, consumo, cultura, entre otros aspectos. Es la composición por sexo, edad, color o raza, y demás variables, lo que puede facilitar la diferenciación de las actividades humanas, tanto desde el punto de vista de su estudio sociológico como de lo económico. Son identificadas a través de ellas una población urbana o rural, una colectividad étnica o nacional, en fin, grupos de individuos clasificados de acuerdo con sus características demográficas que, si son conjugadas con aspectos económicos, posibilitan análisis desde diferentes ángulos de la vida social a lo largo de un determinado periodo. En general, el estudio de los desplazamientos populares está intrínsecamente vinculado al estudio de factores sociológicos y geográficos, ya que cualquier movimiento migratorio, que cambia en la intensidad de una década para otra, puede estar relacionado con factores geográficos, económicos y sociales. Siendo así, el número analizado en forma dinámica traduce en grupos de individuos, como los que registramos aquí, demostrando el crecimiento y la decadencia de los grupos religiosos y sus complejidades.

Las estadísticas religiosas, a pesar de sus limitaciones, han sido reapropiadas y difundidas, no solo por los medios de comunicación, sino también por otras instituciones. Una vez habiendo salido en los medios de comunicación de masas, pueden causar reacciones negativas de los individuos o de los grupos insatisfechos con su clasificación. No es raro que algunos grupos reclamen juntamente con el IBGE (Instituto Brasilero de Geografía y Estadística) la inexpresividad numérica en la cual aparecen representados, y todo porque el espacio reservado para la interpretación de las complejidades del terreno religioso no corresponde con sus necesidades reales de una traducción más precisa de su identidad y representación. Sin embargo, aun así estas estadísticas cumplen su función de contribuir al registro de la memoria de un país, permitiendo el conocimiento de las características de su población y de sus fluctuaciones a lo largo del tiempo. Con eso permiten el debate, la reflexión sobre conceptos complejos, como los de la religión y la secularización, abordados desde diferentes puntos de vista, señalando acuerdos y desacuerdos sobre las identidades que forman parte de la historia del mundo. Entre estas identidades, registramos aquí la memoria del surgimiento y evolución de la categoría censitaria de los sin religión, emblemática no solo de una crisis de pertenencia institucional, sino también de una nueva forma de creer, presente en el ámbito nacional e internacional, donde la religión se convierte en una cuestión de carácter íntimo. 


\section{REFERENCIAS}

Bauman, Z. (1998). O Mal-Estar da Pós-modernidade. Rio de Janeiro: Jorge Zahar Editores.

Berger, P. (1985). O Dossel Sagrado. São Paulo: Paulus.

Berger, P. (2001). A dessecularização do mundo: uma visão global. Religiäo \& Sociedade, 21(1), 9-24. Rio de Janeiro: ISER.

Blancarte, R. (2006). Laicidad y Multiculturalismo: nuevos desafios. En Martínez, G., Daniel. (org.). Multiculturalismo: desafíos y perspectivas, 148-156. México: Siglo XXI.

Da Costa, N. (2006). Laicidad em América latina y Europa: repensando lo religioso entre lo público y lo privado en el siglo XXI. Uruguay: Instituto Universitario CLAEH-Red Puertas.

Hervieu-Léger, D. (1997). Representam os surtos emocionais contemporâneos o fim da secularização ou o fim da religiâo? Religiâo \& Sociedade, 18(1), 31-47. Rio de Janeiro: ISER.

Hervieu-Léger, D. (1999). Le Pèlerin et le converti: La religion em mouvement. France: Flammarion.

Hervieu-Léger, D. (2000). Religion as a chain of memory. New Brunswick, New Jersey: Rutgers University Press.

Instituto Brasileiro de Geografia e Estatística (IBGE). (2010). Sidra 2000-2010. Rio de Janeiro: IBGE, Disponível em www.sidra.ibge.gov.br

Instituto de Pesquisa Econômica Aplicada (IPEA). (2000). Índice de Desenvolvimento Humano-IDH. Rio de Janeiro: IPEA. Disponível em www.ipeadata.gov.br

Mariz, C. (abril, 2001). Secuarização e dessecularização: comentários a um texto de Peter Berger. Religiāo \& Sociedade, 21(1), 25-39. Rio de Janeiro: ISER. 
Marramao, G. (1995). Poder e Secularização: as categorias do tempo. São Paulo: Fundação Editora da Unesp.

Marramao, G. (1997). Céu e Terra: genealogia da secularização. São Paulo: Fundação Editora da Unesp.

Martelli, S. (1995). A religião na sociedade pós-moderna. São Paulo: Paulinas.

Pierucci, A. F. (noviembre, 1997). Reencantamento e Dessecularização - a propósito do auto-engano em Sociologia da Religião. Novos Estudos, 49, 99-117. São Paulo: Cebrap.

Pierucci, A. F. (2000). Secularização segundo Max Weber: da contemporânea serventia de voltarmos a acessar um velho sentido. En Souza, J. (Org.). A atualidade de Max Weber, 105-162. Brasília: UNB.

Pierucci, A. F. (2003). O desencantamento do mundo: Todos os passos do conceito de Max Weber. Sáo Paulo: Editora 34.

Pierucci, A. F. (set/dez., 2004). Bye Bye Brasil - o declínio das religióes tradicionais no Censo 2000. Estudos Avançados, 52, 17-46. São Paulo: IEA/USP.

Pierucci, A. F. (julio, 2006). Religião como solvente - uma aula. Novos Estudos, 75, 111-127. São Paulo: CEBRAP.

Rivera, P. B. (2001). Tradição, transmissão e emoção religiosa: Sociologia do protestantismo contemporâneo na América Latina. São Paulo: Olho D’Água.

Velasco, D. (2006). La construcción histórico-ideológica de la laicidad. In da Costa, N. Laicidad em América Latina y Europa: repensando lo religioso entre lo público y lo privado em el siglo XXI, 14-31. Uruguay: Instituto Universitário CLAEH-Red Puertas.

Weber, M. (1972). Rejeições Ciência como Vocação. In: Weber, M. Ciência e Política: duas vocaçôes, 17-52. São Paulo: Cultrix. 